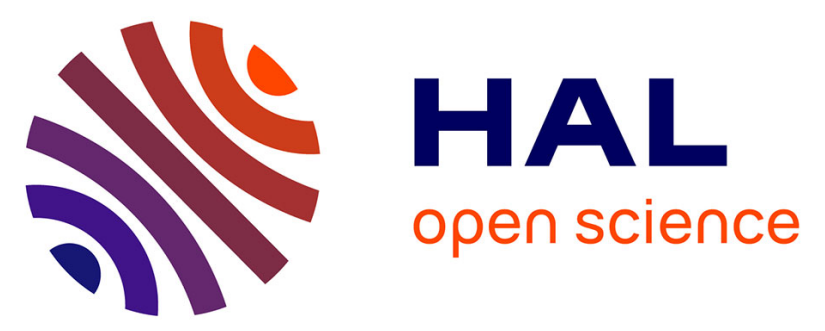

\title{
First crystal structures of oxo-bridged [CrIIITaV] dinuclear complexes Spectroscopic, magnetic and theoretical investigations of the $\mathrm{Cr}-\mathrm{O}$-Ta core
}

L. Androš Dubraja, M. Jurić, W. Lafargue-Dit-Hauret, D. Pajić, A. Zorko, A.

Ozarowski, X. Rocquefelte

\section{To cite this version:}

L. Androš Dubraja, M. Jurić, W. Lafargue-Dit-Hauret, D. Pajić, A. Zorko, et al.. First crystal structures of oxo-bridged [CrIIITaV] dinuclear complexes Spectroscopic, magnetic and theoretical investigations of the Cr-O-Ta core. New Journal of Chemistry, 2018, 42 (13), pp.10912-10921. 10.1039/c8nj01493k . hal-01835067

\section{HAL Id: hal-01835067}

https://hal-univ-rennes1.archives-ouvertes.fr/hal-01835067

Submitted on 10 Sep 2018

HAL is a multi-disciplinary open access archive for the deposit and dissemination of scientific research documents, whether they are published or not. The documents may come from teaching and research institutions in France or abroad, or from public or private research centers.
L'archive ouverte pluridisciplinaire HAL, est destinée au dépôt et à la diffusion de documents scientifiques de niveau recherche, publiés ou non, émanant des établissements d'enseignement et de recherche français ou étrangers, des laboratoires publics ou privés. 


\title{
First crystal structures of oxo-bridged [ $\left.\mathrm{Cr}^{11 \prime} \mathrm{Ta}{ }^{\mathrm{V}}\right]$ dinuclear complexes: spectroscopic, magnetic and theoretical investigations of $\mathrm{Cr}-\mathrm{O}-\mathrm{Ta}$ core
}

\author{
Lidija Androš Dubraja, ${ }^{* a}$ Marijana Jurić, ${ }^{a}$ William Lafargue-Dit-Hauret ${ }^{b}$, Damir Pajić, ${ }^{c}$ Andrej Zorko, ${ }^{d}$ \\ Andrew Ozarowski, ${ }^{\mathrm{e}}$ and Xavier Rocquefelte ${ }^{\mathrm{b}}$
}

\begin{abstract}
Heterodinuclear complexes $\left[\mathrm{Cr}(\mathrm{bpy})_{2}\left(\mathrm{H}_{2} \mathrm{O}\right)(\mu-\mathrm{O}) \mathrm{Ta}_{(}\left(\mathrm{C}_{2} \mathrm{O}_{4}\right)_{3}\right]_{2} \cdot 3.5 \mathrm{H}_{2} \mathrm{O}(\mathbf{1})$ and $\left[\mathrm{H}_{2}(\right.$ terpy $\left.)\right]\left[\mathrm{Cr}(\right.$ terpy $)\left(\mathrm{C}_{2} \mathrm{O}_{4}\right)(\mu-$ 0) $\left.\mathrm{Ta}\left(\mathrm{C}_{2} \mathrm{O}_{4}\right)_{3}\right] \cdot 0.5 \mathrm{H}_{2} \mathrm{C}_{2} \mathrm{O}_{4} \cdot 2.5 \mathrm{H}_{2} \mathrm{O}(2)\left(\mathrm{bpy}=2,2^{\prime}\right.$-bipyridine; terpy $=2,2^{\prime}: 6^{\prime}, 2^{\prime \prime}$-terpyridine) have been synthesised through a reaction of tris(oxalate)oxotantalate( $\mathrm{V}$ ) anion and complex chromium(III) cation with corresponding aromatic $\mathrm{N}$-donor ligands. These are the first examples of $\mathrm{Cr}-\mathrm{O}-\mathrm{Ta}$ bridge in molecular compounds, and the first report of heterodinuclear complexes prepared from a tris(oxalate)oxotantalate(V) anion as a building block. Structural analysis of both compounds revealed that $\mathrm{Ta}^{\mathrm{v}}$ in pentagonal bipyramid geometry is connected through a slightly bent $\mu-\mathrm{O}$ bridge to $\mathrm{Cr}^{\text {"II }}$ having distorted octahedral environment. The geometry optimization performed with density functional theory (DFT) calculations gave very good agreement with experimentally obtained structure of 1 . Room temperature solid state UV-Vis spectra were recorded for both compounds and compared to those of starting reagents, in order to test for possible new electronic transition attributed to the metal-to-metal charge transfer between $\mathrm{Cr}^{\mathrm{III}}$ and $\mathrm{Ta}^{\mathrm{V}}$ through the oxo-bridge. Infrared (IR) spectroscopy supported with DFT calculations was used to assign vibrational modes to all spectral features, especially those coming from molecular $\mu$-oxo bridge. Temperature dependence of magnetic properties was probed with magnetic susceptibility measurements on a SQUID magnetometer. Additionally, zero-filed splitting parameters were determined from electron paramagnetic resonance (EPR) spectra of compound $\mathbf{1}$ and experimentally obtained values were confirmed by DFT calculations.
\end{abstract}

\section{Introduction}

The oxo-bridged metal units are interesting intramolecular motifs appearing in several bioinorganic molecules such as metalloproteins (Fe-O-Fe core) and in various inorganic systems, especially as polyoxometallates, materials with outstanding properties and functions. ${ }^{1,2}$ Recent studies addressing the assembly of oxo-bridged heterobimetallic molecules on the surfaces of mesoporous silica have revealed that such systems possess metal-to-metal charge transfer (MMCT) absorptions across the visible region. ${ }^{3,4}$ This type of multicomponent materials have provided valuable insight in the development of artificial photosynthesis; particularly since such

${ }^{a}$ Ruđer Bošković Institute, Bijenička cesta 54, 10000 Zagreb, Croatia E-mail: lidija.andros@irb.hr; Tel: +38514561184

bInstitut des Sciences Chimiques de Rennes, UMR CNRS 6226, Université de Rennes 1, 263 Avenue du Général Leclerc, 35042 Rennes, France

'Department of Physics, Faculty of Science, University of Zagreb, Bijenička cesta 32, 10000 Zagreb, Croatia

dJožef Stefan Institute, Jamova cesta 39, 1000 Ljubljana, Slovenia

eNational High Magnetic Field Laboratory, Florida State University, Tallahassee,

Florida 32310, USA

tElectronic Supplementary Information (ESI) available: geometric parameters of the metal coordination spheres (Table S1-S3), hydrogen bonding (Table S4), stacking interactions (Table S5). Crystallographic data for $\mathbf{1}$ and $\mathbf{2}$ have been deposited with the Cambridge Crystallographic Data Centre as supplementary publication numbers CCDC 1587289 and 1832563. robust charge-transfer chromophores can drive multi-electron transfer catalysts for water oxidation, carbon dioxide reduction or hydrogen evolution with visible light. ${ }^{5}$ Moreover, computational studies on doped oxides, such as $\mathrm{Ce}^{3+}, \mathrm{Yb}^{3+-}$ codoped $\mathrm{Y}_{3} \mathrm{Al}_{5} \mathrm{O}_{12}$ (YAG), have confirmed that $\mathrm{MMCT}$ transitions play an important role in energy-transfer processes responsible for superior optical properties of these materials. ${ }^{6}$ Metal oxo complexes can be in a particular manner considered as isolated or discrete fragments of oxides, and therefore similar pattern of behaviour can be expected to occur. ${ }^{7}$ For instance, photochemical behaviour was observed in the oxo-bridged complexes of the first row transition metals. ${ }^{8-11}$ The redox properties of such complexes can be tuned by changing the ligands and metals, allowing thus the design of new materials for solar energy conversion applications. ${ }^{10}$ Even though there are several reports of light- and temperature-induced MMCT in metal-organic complexes, the occurrence of this intriguing phenomena is hard to predict and the relationship between electron transfer and molecular structure is not yet understood. ${ }^{12}$ Apart from interesting electronic and optical properties, oxo bridged compounds possess another feature important for potential applications; the oxo bridge can be effective in mediating magnetic exchange interactions between paramagnetic metal centres in complexes. ${ }^{8,13}$ Direct correlation of magnetic properties with light absorption in molecule-based 
compounds is a great challenge and represents a new concept in tuning magnetic properties of materials with potential technological interest.

Our research group has been traditionally involved in studies related to (oxalato)tantalate(V) species, with the aim of obtaining new heterometallic coordination systems with specific (electrical, optical, catalytic and/or magnetic) properties, as well as molecular precursors for mixed-metal oxides. ${ }^{14-17}$ The reactivity of tris(oxalate)oxotantalate( $\mathrm{V}$ ) anion, $\left[\mathrm{TaO}\left(\mathrm{C}_{2} \mathrm{O}_{4}\right)_{3}\right]^{3-}$, which is the most abundant species in the starting reagent - aqueous (oxalato)tantalate solution, strongly depends on the reaction conditions (solvents, other reagents). The oxo group in $\left[\mathrm{TaO}\left(\mathrm{C}_{2} \mathrm{O}_{4}\right)_{3}\right]^{3-}$ can be protonated or replaced with other ligand in the coordination sphere of tantalum $(\mathrm{V})$ and accordingly reactions are directed to products with different topologies and nuclearities. ${ }^{14-17}$

Herein, we report the synthesis, spectroscopic (IR and UV-Vis) and structural characterization of a novel heterodinuclear compounds $\left[\mathrm{Cr}(\mathrm{bpy})_{2}\left(\mathrm{H}_{2} \mathrm{O}\right)(\mu-\mathrm{O}) \mathrm{Ta}\left(\mathrm{C}_{2} \mathrm{O}_{4}\right)_{3}\right]_{2} \cdot 3.5 \mathrm{H}_{2} \mathrm{O} \quad(\mathbf{1})$ and $\left[\mathrm{H}_{2}\right.$ (terpy)][Cr(terpy) $\left.\left(\mathrm{C}_{2} \mathrm{O}_{4}\right)(\mu-\mathrm{O}) \mathrm{Ta}\left(\mathrm{C}_{2} \mathrm{O}_{4}\right)_{3}\right] \cdot 0.5 \mathrm{H}_{2} \mathrm{C}_{2} \mathrm{O}_{4} \cdot 2.5 \mathrm{H}_{2} \mathrm{O}$ (2) (bpy = 2,2'-bipyridine; terpy $=2,2^{\prime}: 6^{\prime}, 2^{\prime \prime}$-terpyridine), where the oxo group, from the $\left[\mathrm{TaO}\left(\mathrm{C}_{2} \mathrm{O}_{4}\right)_{3}\right]^{3-}$ anion is bridged to a chromium(III) ion. This is the first definitive report of a synthesis of heterodinuclear complex using a tris(oxalate)oxotantalate(V) anion and the first structural refinement providing a crystallographic description of a structure containing the $\mathrm{Cr}-\mathrm{O}-$ Ta moieties. Temperature dependent behaviour of compounds $\mathbf{1}$ and $\mathbf{2}$ containing $\mathrm{Cr}^{\mathrm{III}}-\mathrm{O}-\mathrm{Ta}^{\vee}$ fragment was tested by means of magnetic susceptibility measurements on SQUID magnetometer. Additionally, electron paramagnetic resonance spectroscopy was used to determine the zero-filed splitting parameters in compound $\mathbf{1}$, which was supported by density functional theory (DFT) calculations.

\section{Experimental and theoretical methods}

\section{Materials and physical measurements}

The (oxalato)tantalate( $\mathrm{V})$ solution was prepared by dissolving freshly precipitated $\mathrm{Ta}_{2} \mathrm{O}_{5} \cdot n \mathrm{H}_{2} \mathrm{O}$ in $\mathrm{H}_{2} \mathrm{C}_{2} \mathrm{O}_{4} \cdot 2 \mathrm{H}_{2} \mathrm{O}$, according to literature. ${ }^{18}$ The solution of $\left[\mathrm{Cr}(\mathrm{bpy})_{2}\left(\mathrm{H}_{2} \mathrm{O}\right)_{2}\right]\left(\mathrm{NO}_{3}\right)_{3}$ was prepared by refluxing the water-ethanol $(8: 2)$ solution $(8 \mathrm{~mL})$ of $\mathrm{Cr}\left(\mathrm{NO}_{3}\right)_{3} \cdot 9 \mathrm{H}_{2} \mathrm{O}[\mathrm{c}(\mathrm{Cr})=0.05 \mathrm{M}]$ and bipyridine in the molar ratio $1: 2$, following the procedure described previously. ${ }^{19}$ The solution of $\left[\mathrm{Cr}(\right.$ terpy $\left.)\left(\mathrm{H}_{2} \mathrm{O}\right)_{3}\right]\left(\mathrm{NO}_{3}\right)_{3}$ was prepared by refluxing the water-ethanol $(8: 2)$ solution $(8 \mathrm{~mL})$ of $\mathrm{Cr}\left(\mathrm{NO}_{3}\right)_{3} \cdot 9 \mathrm{H}_{2} \mathrm{O}$ and terpyridine in equimolar ratio $[c(\mathrm{Cr})=0.05 \mathrm{M}]$. Elementa analyses for $\mathrm{C}, \mathrm{H}$ and $\mathrm{N}$ were performed with a Perkin-Elmer Model 2400 microanalytical analyser. The infrared spectra were recorded in the $4000-350 \mathrm{~cm}^{-1}$ region with samples as $\mathrm{KBr}$ pellets with a Bruker Alpha FTIR spectrometer. Diffuse reflectance UV-Vis-NIR spectra were obtained at $20^{\circ} \mathrm{C}$ using a Shimadzu UV-Vis-NIR spectrometer (model UV-3600) equipped with an integrated sphere. Barium sulphate was used as reference.

\section{Synthesis}

$\left[\mathrm{Cr}(\mathrm{bpy})_{2}\left(\mathrm{H}_{2} \mathrm{O}\right)(\mu-\mathrm{O}) \mathrm{Ta}\left(\mathrm{C}_{2} \mathrm{O}_{4}\right)_{3}\right]_{2} \cdot 3.5 \mathrm{H}_{2} \mathrm{O}$ (1). An aqueous solution $(2 \mathrm{~mL})$ containing $\left[\mathrm{H}_{3} \mathrm{O}\right]_{3}\left[\mathrm{TaO}\left(\mathrm{C}_{2} \mathrm{O}_{4}\right)_{3}\right][n(\mathrm{Ta})=0.2$ mmol] was added to water-ethanol $(8: 2)$ solution $(8 \mathrm{~mL})$ with $\left[\mathrm{Cr}(\mathrm{bpy})_{2}\left(\mathrm{H}_{2} \mathrm{O}\right)_{2}\right]\left(\mathrm{NO}_{3}\right)_{3}[n(\mathrm{Cr})=0.4 \mathrm{mmol}]$, and stirred for a short period of time. Immediately, a small amount of orange precipitate was formed and removed by filtration. From the resulting clear red solution, orange prismatic crystals of $\mathbf{1}$ rapidly appeared and the process of crystallization was completed within a period of 2 days. The crystals were separated from the solution by filtration, washed with water, and left to dry in air. The yield was $0.068 \mathrm{~g}$ (39.0\%). Anal. Calcd for $\mathrm{C}_{52} \mathrm{H}_{43} \mathrm{Cr}_{2} \mathrm{Ta}_{2} \mathrm{~N}_{8} \mathrm{O}_{31.5}$ : C, 35.69; $\mathrm{H}, 2.48 ; \mathrm{N}, 6.40 \%$. Found: $\mathrm{C}$, 35.42; H, 2.60; N, $6.68 \%$. IR, cm ${ }^{-1}$ : 3448 (m, br), 3121 (w), 3086 (w), 1752 (s), 1720 (vs), 1689 (s), 1679 (vs), 1605 (s), 1567 (w), 1501 (w), $1474(\mathrm{~m}), 1447$ (s), 1384 (vs), 1343 (s), $1319(\mathrm{~m}), 1244$ $(\mathrm{m}), 1225(\mathrm{~m}), 1178(\mathrm{w}), 1162(\mathrm{w}), 1106(\mathrm{w}), 1068(\mathrm{w}), 1036(\mathrm{~m})$, $1022(\mathrm{w}), 935(\mathrm{~m}), 902(\mathrm{~m}), 886(\mathrm{~s}), 869(\mathrm{vs}), 806(\mathrm{~m}), 774(\mathrm{~s})$, $730(\mathrm{~m}), 669(\mathrm{w}), 653(\mathrm{w}), 577(\mathrm{w}), 556(\mathrm{~m}), 539(\mathrm{~m}), 474(\mathrm{~m})$, $454(w), 419(w), 384(w)$.

\section{$\left[\mathrm{H}_{\mathbf{2}}\right.$ (terpy)][Cr(terpy) $\left.\left(\mathrm{C}_{\mathbf{2}} \mathrm{O}_{4}\right)(\boldsymbol{\mu}-\mathrm{O}) \mathrm{Ta}\left(\mathrm{C}_{\mathbf{2}} \mathrm{O}_{4}\right)_{3}\right] \cdot \mathbf{0 . 5} \mathrm{H}_{\mathbf{2}} \mathrm{C}_{\mathbf{2}} \mathrm{O}_{\mathbf{4}} \cdot \mathbf{2} \cdot \mathbf{5} \mathrm{H}_{\mathbf{2}} \mathrm{O}$}

(2). An aqueous solution $(2 \mathrm{~mL})$ containing $\left[\mathrm{H}_{3} \mathrm{O}\right]_{3}\left[\mathrm{TaO}\left(\mathrm{C}_{2} \mathrm{O}_{4}\right)_{3}\right]$ $[n(\mathrm{Ta})=0.2 \mathrm{mmol}]$ was added to water-ethanol $(8: 2)$ solution $(8 \mathrm{~mL})$ with $\left[\mathrm{Cr}(\right.$ terpy $\left.)\left(\mathrm{H}_{2} \mathrm{O}\right)_{3}\right]\left(\mathrm{NO}_{3}\right)_{3}[n(\mathrm{Cr})=0.4 \mathrm{mmol}]$, and reaction mixture was shortly stirred. Immediately, a small amount of greyish precipitate was formed and removed by filtration. From the resulting clear red solution, dark red sticklike crystals of $\mathbf{2}$ started to appear within two days. The crystals were separated from the solution by filtration, washed with water, and left to dry in air. The yield was $0.053 \mathrm{~g}(23 \%)$. Anal. Calcd for $\mathrm{C}_{39} \mathrm{H}_{30} \mathrm{CrTaN}_{6} \mathrm{O}_{21.5}: \mathrm{C}, 40.39 ; \mathrm{H}, 2.60 ; \mathrm{N}, 7.23 \%$. Found: C, 39.92; H, 2.77; N, $7.38 \%$. IR, cm $\mathrm{cm}^{-1}: 3446$ (m, br), $3093(\mathrm{w})$, 1750 (m, sh), 1716 (vs), 1686 (vs), 1614 (m), $1588(\mathrm{~m}), 1574$ (w), $1538(\mathrm{~m}), 1505(\mathrm{w}), 1476(\mathrm{~m}), 1450(\mathrm{~m}), 1371(\mathrm{~s}), 1365(\mathrm{~s}), 1322$ $(\mathrm{m}), 1295(\mathrm{~m}), 1246(\mathrm{~m}), 1166(\mathrm{w}), 1125(\mathrm{w}), 1098(\mathrm{w}), 1042(\mathrm{w})$, $1028(w), 994(w), 940(m), 874(s), 803(s), 781(s), 736(w), 682$ $(w), 657(w), 614(w), 580(w), 556(m), 513(w), 505(w), 482$ $(\mathrm{m}), 465(\mathrm{w}), 445(\mathrm{~m}), 429(\mathrm{w}), 418(\mathrm{w}), 410(\mathrm{w})$.

\section{Single-crystal X-ray study}

The X-ray data of a single crystal of $\mathbf{1}$ were collected by $\omega$-scans on an Oxford Diffraction Xcalibur Nova R diffractometer with a mirror monochromator using $\mathrm{Cu}-\mathrm{K} \alpha$ radiation $(\lambda=1.54179 \AA$, microfocus tube, CCD detector) at 103(2) K. Crystals of 2 were measured on D8 Venture Bruker diffractometer with dual microsource $\mathrm{Ag}-\mathrm{Mo}$ radiation (using Mo-K $\alpha$ radiation, $\lambda=$ $0.71073 \AA$, CCD detector) at 298(2) K. Data reduction, including the absorption correction, was performed with the CrysAlisPRO software ${ }^{20}$ package for compound $\mathbf{1}$, and with the SAINT software $^{21}$ package for compound 2. The crystal data, experimental conditions and final refinement parameters are summarized in Table 1. Molecular and crystal structures were solved by direct methods using the program SIR92, 22 and refined by the full-matrix least-squares method based on $F^{2}$ with anisotropic displacement parameters for all non-hydrogen atoms (SHELXL-2017/1). ${ }^{23}$ Both programs were operating under the WinGX ${ }^{24}$ program package. Hydrogen atoms attached to the $\mathrm{C}$ atoms of the bpy/terpy ligands were treated as riding in 
idealized positions, with the $\mathrm{C}-\mathrm{H}$ distances of $0.93 \AA$ and displacement parameters assigned as $U_{\text {iso }}(H)=1.2 U_{\text {eq }}(C)$. Hydrogen atoms for water molecules with an occupancy factor of 0.5 were not determined. All other hydrogen atoms of the water molecules were identified based on difference Fourier maps $[\mathrm{O}-\mathrm{H}$ distances were restrained to a target value of $0.85(2) \AA$, and the $\mathrm{H}-\mathrm{O}-\mathrm{H}$ angle to $104^{\circ}$ ]. Geometrical calculations were carried out with PLATON ${ }^{25}$ and the figures were generated using VESTA ${ }^{26}$ and CCDC-Mercury ${ }^{27}$ programs.

Table 1 Crystallographic data and structure refinement details for $\left[\mathrm{Cr}(\mathrm{bpy})_{2}\left(\mathrm{H}_{2} \mathrm{O}\right)(\mu\right.$ O) $\left.\mathrm{Ta}\left(\mathrm{C}_{2} \mathrm{O}_{4}\right)_{3}\right]_{2} \cdot 3.5 \mathrm{H}_{2} \mathrm{O}$ (1) and $\left[\mathrm{H}_{2}\right.$ (terpy) $]\left[\mathrm{Cr}(\right.$ terpy $)\left(\mathrm{C}_{2} \mathrm{O}_{4}\right)(\mu$ 0) $\left.\mathrm{Ta}\left(\mathrm{C}_{2} \mathrm{O}_{4}\right)_{3}\right] \cdot 0.5 \mathrm{H}_{2} \mathrm{C}_{2} \mathrm{O}_{4} \cdot 2.5 \mathrm{H}_{2} \mathrm{O}(2)$.

\begin{tabular}{|c|c|c|}
\hline Compound & 1 & 2 \\
\hline$T / \mathrm{K}$ & $103(2)$ & $298(2)$ \\
\hline Crystal colour, habit & orange, prism & red, stick \\
\hline Empirical formula & $\mathrm{C}_{52} \mathrm{H}_{43} \mathrm{Cr}_{2} \mathrm{Ta}_{2} \mathrm{~N}_{8} \mathrm{O}_{31.5}$ & $\mathrm{C}_{39} \mathrm{H}_{30} \mathrm{CrTaN}_{6} \mathrm{O}_{21.50}$ \\
\hline Formula weight/g mol-1 & 1749.82 & 1159.63 \\
\hline Crystal system & Monoclinic & Triclinic \\
\hline Space group & $P 2_{1} / c$ & $P \overline{1}$ \\
\hline$a / \AA ̊$ & $20.224(5)$ & $10.798(2)$ \\
\hline$b / \AA ̊$ & $17.273(5)$ & $10.916(2)$ \\
\hline$c / \AA ̊$ & $18.775(5)$ & $18.810(3)$ \\
\hline$\alpha /^{\circ}$ & 90 & $88.151(8)$ \\
\hline$\beta 1^{\circ}$ & $115.430(5)$ & $82.753(8)$ \\
\hline$\gamma /^{\circ}$ & 90 & $78.767(9)$ \\
\hline$V / \AA^{3}$ & $5923(3)$ & $2157.2(7)$ \\
\hline$Z$ & 4 & 2 \\
\hline$\rho_{\text {calcd }} / \mathrm{g} \mathrm{cm}^{-3}$ & 1.961 & 1.748 \\
\hline$\mu / \mathrm{mm}^{-1}$ & 10.485 & 2.88 \\
\hline$F(000)$ & 3424 & 1148 \\
\hline$\theta$ range $/^{\circ}$ & $3.51-75.74$ & $2.10-27.48$ \\
\hline Measured reflections & 69042 & 143881 \\
\hline Independent reflections & 12277 & 9849 \\
\hline Observed reflections & 12035 & 8629 \\
\hline No. of parameters & 899 & 643 \\
\hline No. of restraints & 14 & 9 \\
\hline$R_{\text {int }}$ & 0.0368 & 0.0351 \\
\hline$R, \mathrm{w} R[\mathrm{I}>2 \sigma(\mathrm{I})]$ & $0.0371,0.0992$ & $0.0411,0.1006$ \\
\hline$R, w R$ [all data] & $0.0377,0.0998$ & $0.0517,0.1099$ \\
\hline Goodness of fit, $S$ & 1.085 & 1.099 \\
\hline$\Delta \rho_{\max }, \Delta \rho_{\min } / \mathrm{e} \AA^{-3}$ & $2.294,-1.545$ & $3.874 ;-1.947$ \\
\hline
\end{tabular}

\section{Magnetic susceptibility and EPR spectroscopy}

The magnetization $M$ of a powder sample of compounds $\mathbf{1}$ and 2 was measured with an MPMS 5 commercial superconducting quantum interferometer device (SQUID) magnetometer. The measured magnetic moments of the sample were corrected by taking into account the sample holder and temperature independent contributions of the core electrons in accordance with the well-known Pascal constants. The temperature dependence of magnetization, $M(T)$, was measured under different magnetic fields, from 1 Oe to $50 \mathrm{kOe}$, in the temperature range $2-300 \mathrm{~K}$. Additionally, the field dependences of magnetization, $M(H)$, was measured at several fixed temperatures in fields up to $50 \mathrm{kOe}$.

The electron paramagnetic resonance (EPR) spectra were recorded on a polycrystalline sample of $\mathbf{1}$ using a commercial resonance-cavity based Bruker Elexsys E580 spectrometer working in the X-band $(9.74 \mathrm{GHz})$ and a high-frequency (52-416 $\mathrm{GHz}$ ) custom-made transmission-type spectrometer. ${ }^{27}$ The latter measurements were performed in the Faraday configuration with the microwave magnetic field being perpendicular to the static applied magnetic field provided by an Oxford superconducting magnet capable of reaching $17 \mathrm{~T}$. Both types of experiments were done in a temperature range between $5 \mathrm{~K}$ and room temperature (RT) using continues Heflow cryostats. The spectra were simulated with the EasySpin software ${ }^{29}$ by calculating the allowed dipolar transitions between all energy levels and powder averaging the results.

\section{First-principles calculations}

Spin-polarized calculations were performed using the density functional theory (DFT) within the Perdew-Burke-Ernzerhof Approximation $(\mathrm{PBE})^{30}$ and the Projected Augmented Wave $(P A W)^{31}$ method as implemented in the Vienna Ab-initio Simulation Package (VASP). ${ }^{32,33}$ The well-known inaccuracy in the treatment of the electronic delocalization of $3 \mathrm{~d}$ states was improved using the $\mathrm{HSEO6}^{34}$ screened hybrid functional and the $\mathrm{PBE}+\mathrm{U}^{35}$ method using the Dudarev scheme. Regarding the last method, a Hubbard effective parameter $U_{\text {eff }}=3.5 \mathrm{eV}$ was set for Chromium 3d states, as previously done for the tetranuclear complex $\left[\mathrm{Cr}_{2}(\text { bpy })_{4}(\mu-\mathrm{O})_{4} \mathrm{Nb}_{2}\left(\mathrm{C}_{2} \mathrm{O}_{4}\right)_{4}\right] \cdot 3 \mathrm{H}_{2} \mathrm{O} \cdot{ }^{36} \quad$ Theoretical investigations were based on the low-temperature experimental structure, molecule with occupation factor 0.5 was neglected. Because complexes are too far from each other to interact magnetically, our study was restricted to a purely antiferromagnetic case (i.e. antiparallel magnetic moments on the two crystallographic inequivalent $\mathrm{Cr}$ sites). The geometry optimization was performed within the $\mathrm{PBE}+\mathrm{U}$ level and with an energy cut-off of $300 \mathrm{eV}$. Only ionic positions were allowed to relax to reach a convergence criterion of $0.001 \mathrm{eV} \mathrm{A}^{-1}$ on the atomic forces. Once geometrical relaxations were done, electronic, vibrational and magnetic properties were studied using more accurate computational conditions and considering only one complex extracted from the experimental and optimized crystal structures. Vibrational transitions were determined using an increased energy cut-off of $350 \mathrm{eV}$. The harmonic frequencies were determined using the finite central difference method and an atomic displacement set to $0.015 \AA$. The single-ion anisotropy of the $\mathrm{Cr}$ atom of a complex was studied using non-ultrasoft pseudopotentials which lead to increase the cut-off energy at $500 \mathrm{eV}$, including also the spinorbit coupling in a perturbative approach. During the study, the choice of the $U_{\text {eff }}$ value was checked comparing results obtained with the hybrid functional HSE06. For all calculations, only the Gamma point was taken into account.

\section{Results and discussion}

\section{Synthesis}

The heterodinuclear oxo-bridged compound $\left[\mathrm{Cr}(\mathrm{bpy})_{2}\left(\mathrm{H}_{2} \mathrm{O}\right)(\mu\right.$ O) $\left.\mathrm{Ta}\left(\mathrm{C}_{2} \mathrm{O}_{4}\right)_{3}\right]_{2} \cdot 3.5 \mathrm{H}_{2} \mathrm{O}(\mathbf{1})$ is obtained as the primary product when aqueous solutions containing $\mathrm{TaO}\left(\mathrm{C}_{2} \mathrm{O}_{4}\right)^{3-}$ anions and 
water/ethanol solution of $\left[\mathrm{Cr}(\mathrm{bpy})_{2}\left(\mathrm{H}_{2} \mathrm{O}\right)_{2}\right]\left(\mathrm{NO}_{3}\right)_{3}$ are mixed together (Scheme 1). Compound $\left[\mathrm{H}_{2}\right.$ (terpy)] $\left[\mathrm{Cr}\left(\right.\right.$ terpy) $\left(\mathrm{C}_{2} \mathrm{O}_{4}\right)(\mu$ O) $\left.\mathrm{Ta}\left(\mathrm{C}_{2} \mathrm{O}_{4}\right)_{3}\right] \cdot 0.5 \mathrm{H}_{2} \mathrm{C}_{2} \mathrm{O}_{4} \cdot 2.5 \mathrm{H}_{2} \mathrm{O}$ (2) is prepared following the same procedure, but using $\left[\mathrm{Cr}(\right.$ terpy $\left.)\left(\mathrm{H}_{2} \mathrm{O}\right)_{3}\right]\left(\mathrm{NO}_{3}\right)_{3}$ as a source of chromium(III) ions. The best yield is achieved if $\mathrm{Cr}$ : Ta ratio of 2: 1 is taken. New compounds are insoluble in common organic solvents and only slightly soluble in acidic media.

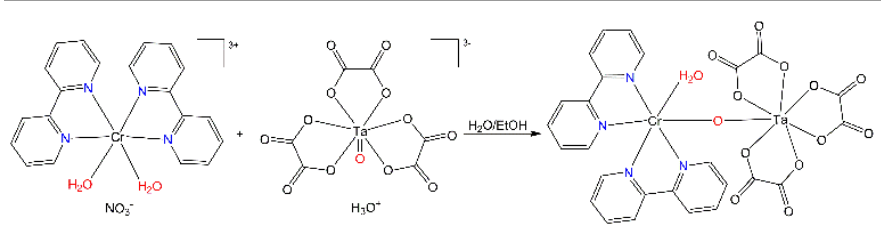

Scheme 1. Synthesis of compound 1 through reaction of bis(bipyridine)chromium(III) cation and tris(oxalate)oxotantalate(V) anion in water/ethanol solution.

(Oxalato)tantalates $(\mathrm{V})$ are one of the few systems of tantalum stable in aqueous solution, and they are prepared by dissolving freshly precipitated tantalum oxide $\left(\mathrm{Ta}_{2} \mathrm{O}_{5} \cdot n \mathrm{H}_{2} \mathrm{O}\right)$ in excess of oxalic acid. ${ }^{37}$ As a consequence, such a solution contains more oxalate anions than it is needed for coordinating the tantalum(V) ion. In our previous studies we have shown that the (oxalato)tantalate solution can contain at least three different (oxalato)tantalate anions: the most abundant $\left[\mathrm{TaO}\left(\mathrm{C}_{2} \mathrm{O}_{4}\right)_{3}\right]^{3-}$ and two other forms $\left[\mathrm{Ta}\left(\mathrm{C}_{2} \mathrm{O}_{4}\right)_{4}\right]^{3-}$ and $\left[\mathrm{Ta}(\mathrm{OH})\left(\mathrm{C}_{2} \mathrm{O}_{4}\right)_{3}\right]^{2-} .{ }^{24-17}$ Herein, the $\left[\mathrm{TaO}\left(\mathrm{C}_{2} \mathrm{O}_{4}\right)_{3}\right]^{3-}$ anions with terminal oxo group, act as a Lewis base to a chromium(III) ions. One water molecule from $\left[\mathrm{Cr}(\mathrm{bpy})_{2}\left(\mathrm{H}_{2} \mathrm{O}\right)_{2}\right]^{3+}$ cation is replaced with the bridging $\mu-\mathrm{O}$ atom and neutral dinuclear compound $\mathbf{1}$ with $\mathrm{Cr}-\mathrm{O}-\mathrm{Ta}$ core is formed. Precursor solution of $\left[\mathrm{Cr}(\text { terpy })\left(\mathrm{H}_{2} \mathrm{O}\right)_{3}\right]^{3+}$ cations undergoes ligand rearrangements in reaction mixture: one oxalate anion, available from the (oxalato)tantalate solution, replaces two water molecules in coordination sphere of chromium. The new $\left[\mathrm{Cr}(\text { terpy })\left(\mathrm{C}_{2} \mathrm{O}_{4}\right)\left(\mathrm{H}_{2} \mathrm{O}\right)\right]^{+}$complex cation reacts with $\left[\mathrm{TaO}\left(\mathrm{C}_{2} \mathrm{O}_{4}\right)_{3}\right]^{3-}$ anions, resulting in formation of oxo-

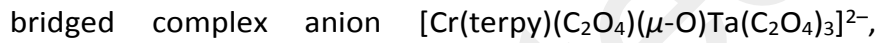
crystalizing along with di-protonated terpyridine cations, oxalic acid and water molecules as compound $\mathbf{2}$. Presence of free terpyridinum cations in the reaction mixture points to lover stability of initial $\left[\mathrm{Cr}(\text { terpy })\left(\mathrm{H}_{2} \mathrm{O}\right)_{3}\right]^{3+}$ precursor solution, compared to solution of $\left[\mathrm{Cr}(\mathrm{bpy})_{2}\left(\mathrm{H}_{2} \mathrm{O}\right)_{2}\right]^{3+}$ cations.

\section{Crystal structures}

Compound 1 crystallizes in the monoclinic $P 2_{1} / c$ space group as orange crystals (Table 1 ). The asymmetric unit consists of two dinuclear $\left[\mathrm{Cr}(\mathrm{bpy})_{2}\left(\mathrm{H}_{2} \mathrm{O}\right)(\mu-\mathrm{O}) \mathrm{Ta}\left(\mathrm{C}_{2} \mathrm{O}_{4}\right)_{3}\right]$ moieties (Fig. 1), and 3.5 water molecules of crystallization. Compound $\mathbf{2}$ crystallizes in triclinic $P \overline{1}$ space groups, having terpyridinium cation and dinuclear $\left[\mathrm{Cr}(\text { terpy })\left(\mathrm{C}_{2} \mathrm{O}_{4}\right)(\mu-\mathrm{O}) \mathrm{Ta}\left(\mathrm{C}_{2} \mathrm{O}_{4}\right)_{3}\right]^{2-}$ anion (Fig. 2), one half of oxalic acid and two and a half of water molecules of crystallization in the asymmetric unit.

The Crlll ion displays a distorted octahedral coordination in both compounds: in $\mathbf{1}$ involving four $\mathrm{N}$ atoms from two coordinated bpy molecules, one bridging oxo atoms and one $\mathrm{O}$ atom (O1 in Fig. 1) from coordinated water molecule; in $\mathbf{2}$ three $\mathrm{N}$ atoms from terpy molecule, two $\mathrm{O}$ atoms from coordinated oxalate group and one bridging oxo atom. The values of the $\mathrm{Cr}-\mathrm{N}$ bond distances are in good agreement with bond lengths in similar chromium(III) complexes. ${ }^{19,36,38} \mathrm{The} \mathrm{Cr}-\mathrm{O}_{\text {water }}$ bond distances in 1 are, as expected, longer than the $\mathrm{Cr}-\mathrm{O}_{\text {oxo }}$ (Table 2). Compared to compound $\left[\mathrm{Cr}(\mathrm{bpy})_{2}(\mu-\mathrm{O})_{2} \mathrm{Nb}\left(\mathrm{C}_{2} \mathrm{O}_{4}\right)_{2}\right]_{2} \cdot 3 \mathrm{H}_{2} \mathrm{O},{ }^{36}$ the $\mathrm{Cr}-\mathrm{O}_{\text {oxo }}$ bonds lengths in $\mathbf{1}$ and $\mathbf{2}$ are slightly shorter, whereas the Ta$\mathrm{O}_{\text {oxo }}$ are of similar values to $\mathrm{Nb}-\mathrm{O}_{\text {oxo }}$ bond lengths (Table 2 ). The shorter $\mathrm{Cr}-\mathrm{O}_{\text {oxo }}$ bond length can be explained by the less rigid geometry of the dinuclear unit compared to tetranuclear unit. This is confirmed by the fact that in the trinuclear $\left.\left[\mathrm{Cr}_{2} \text { (terpy }\right)_{2}\left(\mathrm{C}_{2} \mathrm{O}_{4}\right)_{2}(\mu-\mathrm{O})_{2} \mathrm{Nb}\left(\mathrm{C}_{2} \mathrm{O}_{4}\right)_{2}\right]^{-}$unit ${ }^{38}$ the $\mathrm{Cr}-\mathrm{O}_{\text {oxo }}$ bond lengths are approximately the same as in $\mathbf{1}$ and $\mathbf{2}$. Selected bond lengths and angles describing coordination geometry around metal centres in $\mathbf{1}$ and $\mathbf{2}$ are given in $\mathrm{ESI}+$ (Tables S1-S3).

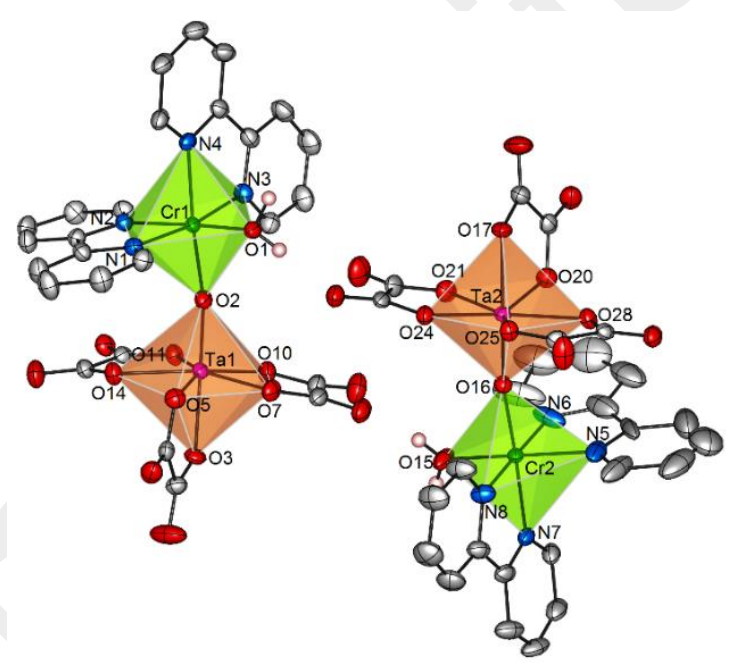

Fig. 1 VESTA ${ }^{26}$ drawing of the heterodinuclear $\left[\mathrm{Cr}(\mathrm{bpy})_{2}\left(\mathrm{H}_{2} \mathrm{O}\right)(\mu-\mathrm{O}) \mathrm{Ta}\left(\mathrm{C}_{2} \mathrm{O}_{4}\right)_{3}\right]$ units in 1, showing atoms as ellipsoids with $50 \%$ probability. Coordination polyhedra around metal centres are depicted: the octahedron around $\mathrm{Cr}$ in green and the pentagonal bipyramid around Ta in red colours. Hydrogen atoms belonging to bpy molecules are omitted for clarity.

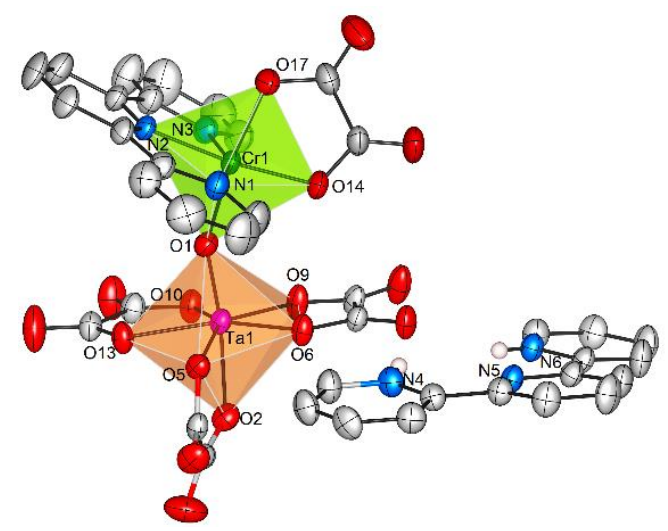

Fig. 2 VESTA ${ }^{26}$ drawing of the $\left[\mathrm{H}_{2} \text { (terpy) }\right]^{2+}$ cation and $\left[\mathrm{Cr}(\right.$ terpy $)\left(\mathrm{C}_{2} \mathrm{O}_{4}\right)(\mu$ O) $\left.\mathrm{Ta}\left(\mathrm{C}_{2} \mathrm{O}_{4}\right)_{3}\right]^{2-}$ anion in $\mathbf{2}$, showing atoms as ellipsoids with $50 \%$ probability. Coordination polyhedra around metal centres are depicted: the octahedron around $\mathrm{Cr}$ in green and the pentagonal bipyramid around Ta in red colours. Aromatic hydrogen atoms belonging to terpy and $\left[\mathrm{H}_{2}(\text { terpy })\right]^{2+}$ molecules are omitted for clarity.

Based on the bond valence analysis ${ }^{39}$ the Ta- $\mathrm{O}_{\text {oxo }}$ bonds in $\mathbf{1}$ and 2, even though longer than the double $\mathrm{Ta}=\mathrm{O}$ bond lengths in $\left[\mathrm{TaO}\left(\mathrm{C}_{2} \mathrm{O}_{4}\right)_{3}\right]^{3-}$ anions, ${ }^{15,16}$ still show indication of some amount 
of double bond character (Table 2). The distorted pentagonal bipyramid geometry around $\mathrm{Ta}^{\mathrm{V}}$ in $\mathbf{1}$ and $\mathbf{2}$ is close to other structurally characterized seven-coordinated tantalum(V) complexes, having two oxalate ligands in the equatorial plane, one bridging oxo ligand in axial position and one oxalate ligand sharing axial and equatorial position (Fig. 1 and 2). ${ }^{14-17}$ Probably due to more rigid and bulkier terpy geometry, the $\mathrm{Cr}-\mathrm{O}-\mathrm{Ta}$ bridge in 2 is less linear [153.5(2) ${ }^{\circ}$ than in $\mathbf{1}$ [169.7(2) and $\left.170.2(9)^{\circ}\right]$.

Table 2. Selected bond lengths ( $(\AA)$ and valences (valence unit) in 1, 2 and structurally related compounds.

\begin{tabular}{|c|c|c|c|c|c|c|}
\hline \multirow{2}{*}{ Compound } & length & valence & length & valence & length & valence \\
\hline & \multicolumn{2}{|c|}{$\mathrm{Ta}-\mathrm{O}_{\text {oxo }}$} & \multicolumn{2}{|c|}{$\mathrm{Cr}-\mathrm{O}_{\text {oxo }}$} & \multicolumn{2}{|c|}{$\mathrm{Cr}-\mathrm{O}_{\text {water }}$} \\
\hline \multirow[t]{2}{*}{1} & $1.805(3)$ & 1.36 & $1.902(3)$ & 0.62 & $1.964(3)$ & 0.52 \\
\hline & $1.809(3)$ & 1.35 & $1.893(3)$ & 0.63 & $1.960(4)$ & 0.53 \\
\hline \multirow[t]{2}{*}{2} & $1.797(3)$ & 1.39 & $1.905(3)$ & 0.61 & - & \\
\hline & \multicolumn{2}{|c|}{$\mathrm{Nb}-\mathrm{O}_{\text {oxo }}$} & & & & \\
\hline \multirow[t]{4}{*}{ Ref. $36^{a}$} & $1.794(4)$ & 1.37 & $1.897(4)$ & 0.63 & \multirow{4}{*}{\multicolumn{2}{|c|}{ - }} \\
\hline & $1.797(4)$ & 1.36 & $1.907(4)$ & 0.61 & & \\
\hline & $1.800(4)$ & 1.35 & $1.912(4)$ & 0.60 & & \\
\hline & $1.801(4)$ & 1.35 & $1.922(4)$ & 0.59 & & \\
\hline \multirow[t]{3}{*}{ Ref. $38^{b}$} & $1.792(2)$ & 1.38 & $1.927(2)$ & 0.58 & \multirow{2}{*}{$1.975(3)$} & \multirow{2}{*}{0.51} \\
\hline & $1.808(2)$ & 1.32 & $1.922(2)$ & 0.59 & & \\
\hline & \multicolumn{2}{|c|}{$\mathrm{Ta}=\mathrm{O}$} & & & & \\
\hline Ref. $16^{c}$ & $1.748(5)$ & 1.59 & \multicolumn{2}{|c|}{-} & \multicolumn{2}{|c|}{-} \\
\hline Ref. $15^{d}$ & $1.742(4)$ & 1.63 & \multicolumn{2}{|c|}{-} & \multicolumn{2}{|c|}{-} \\
\hline
\end{tabular}

${ }^{a}\left[\mathrm{Cr}(\text { bpy })_{2}(\mu-\mathrm{O})_{2} \mathrm{Nb}\left(\mathrm{C}_{2} \mathrm{O}_{4}\right)_{2}\right]_{2} \cdot 3 \mathrm{H}_{2} \mathrm{O} ;{ }^{b}\left[\mathrm{Cr}(\right.$ terpy $\left.)\left(\mathrm{C}_{2} \mathrm{O}_{4}\right)\left(\mathrm{H}_{2} \mathrm{O}\right)\right]\left[\mathrm{Cr}_{2}(\text { terpy })_{2}\left(\mathrm{C}_{2} \mathrm{O}_{4}\right)_{2}(\mu-\right.$ O) $\left.{ }_{2} \mathrm{Nb}\left(\mathrm{C}_{2} \mathrm{O}_{4}\right)_{2}\right] \cdot 3 \mathrm{H}_{2} \mathrm{O} ;{ }^{c}\left[\mathrm{Ni}(\mathrm{bpy})_{3}\right]_{2}\left[\mathrm{TaO}\left(\mathrm{C}_{2} \mathrm{O}_{4}\right)_{3}\right] \cdot 11 \mathrm{H}_{2} \mathrm{O}$;

$d\left\{\mathrm{Ba}_{2}\left(\mathrm{H}_{2} \mathrm{O}\right)_{5}\left[\mathrm{TaO}\left(\mathrm{C}_{2} \mathrm{O}_{4}\right)_{3}\right] \mathrm{HC}_{2} \mathrm{O}_{4}\right\} \cdot \mathrm{H}_{2} \mathrm{O}$.

Atomic structure of $\mathbf{1}$ has been used as the starting point for the theoretical geometry optimization. For this purpose $\mathrm{PBE}+\mathrm{U}$ functional with Ueff $=3.5 \mathrm{eV}$ for $3 \mathrm{~d}(\mathrm{Cr})$ states was used. A comparison of the bond lengths involved in the first coordination sphere of tantalum and chromium atoms is provided in Table S1 of ESIt. Very small deviations between experimental and theoretical data are observed (less than $2.2 \%)$, confirming the validity of the present theoretical approach. In addition, bond distances are slightly overestimated as expected when using GGA-PBE functional. Interestingly, our calculations allow to provide relaxed atomic positions of the hydrogen atoms of the water molecules in their equilibrium geometry. Indeed, experimentally, the hydrogen atoms were fixed based on geometrical arguments with a defined $\mathrm{O}_{\text {water }}-\mathrm{H}$ bond length value of $0.85 \AA$. The average optimized $\mathrm{O}_{\text {water }}-\mathrm{H}$ bond length value is $1.024 \AA$.

Interesting hydrogen bonding network between water molecules and dinuclear $\left[\mathrm{Cr}(\mathrm{bpy})_{2}\left(\mathrm{H}_{2} \mathrm{O}\right)(\mu-\mathrm{O}) \mathrm{Ta}\left(\mathrm{C}_{2} \mathrm{O}_{4}\right)_{3}\right]$ units is observed in 1: each crystallization water molecule acts as proton donor for one neighbouring solvate water molecule and one neighbouring oxalate ligand from dinuclear unit. The crystallization water molecules are interconnected forming isolated hexagonal rings (Fig. 3a). It should be noted that such a motif has been observed in very few structures in the CSD. ${ }^{40}$ Each dinuclear $\left[\mathrm{Cr}(\mathrm{bpy})_{2}\left(\mathrm{H}_{2} \mathrm{O}\right)(\mu-\mathrm{O}) \mathrm{Ta}\left(\mathrm{C}_{2} \mathrm{O}_{4}\right)_{3}\right]$ unit contains one coordinated water molecule, which forms additional hydrogen bonds with two neighbouring dinuclear units. The overall supramolecular hydrogen bonding architecture is two- dimensional in the $b c$ plane. Water molecule with occupancy 0.5 is located outside the 2D-hydrogen bonding network, filling residual void between layers. Extended hydrogen bonding is observed in 2, involving $\left[\mathrm{Cr}(\text { terpy })\left(\mathrm{C}_{2} \mathrm{O}_{4}\right)(\mu-\mathrm{O}) \mathrm{Ta}\left(\mathrm{C}_{2} \mathrm{O}_{4}\right)_{3}\right]^{2-}$ anions, terpyridinum cations, oxalic acid and crystallization water molecules (Fig. 3b). In $2 \pi$-stacking interactions are additionally stabilizing the crystal structure (Fig. 4). Geometric parameters describing the hydrogen bonding network and stacking interactions are given in Tables S4 and S5 in the ESIt.

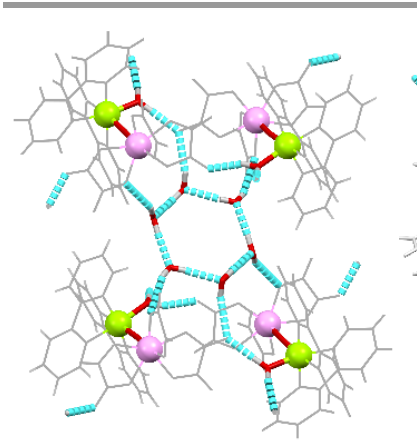

(a)

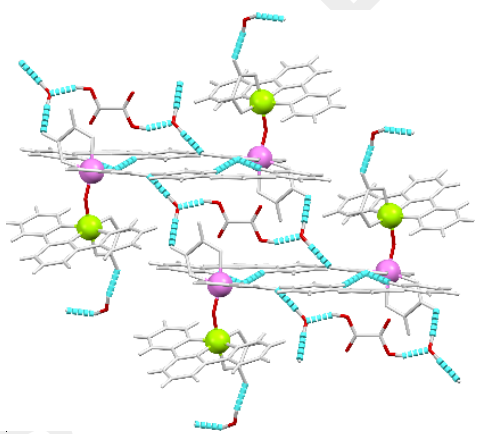

(b)
Fig. 3. Hydrogen bonding between $\left[\mathrm{Cr}(\mathrm{bpy})_{2}\left(\mathrm{H}_{2} \mathrm{O}\right)(\mu-\mathrm{O}) \mathrm{Ta}\left(\mathrm{C}_{2} \mathrm{O}_{4}\right)_{3}\right]$ units and water molecules of crystallization in $\mathbf{1}(\mathrm{a})$, and between $\left[\mathrm{Cr}(\mathrm{terpy})\left(\mathrm{C}_{2} \mathrm{O}_{4}\right)(\mu-\mathrm{O}) \mathrm{Ta}\left(\mathrm{C}_{2} \mathrm{O}_{4}\right)_{3}\right]^{2-}$ anions, terpyridinum cations, oxalic acid and crystallization water molecules in $\mathbf{2}$ (b). $\mathrm{Cr}$ atoms are depicted in green and Ta atoms in pink.

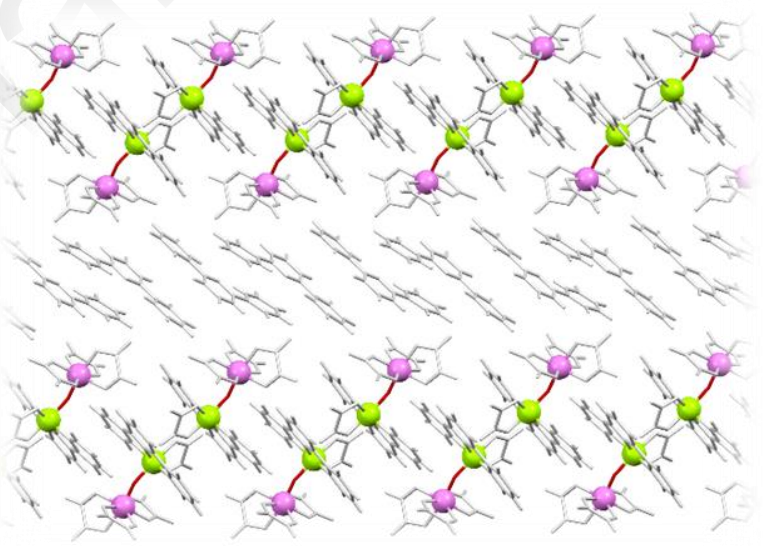

Fig. 4. Representation of aromatic stacking interactions in $\mathbf{2}$.

\section{UV-Vis spectroscopy}

Oxo-bridged compounds with $d^{3}-d^{0}$ electronic configuration inside the $\mathrm{M}-\mathrm{O}-\mathrm{M}^{\prime}$ core, having $\mathrm{Cr}^{\prime \prime \prime}$ as electron donor and $\mathrm{Ti}^{\mathrm{IV}}$ as electron acceptor, ${ }^{9,10}$ have shown to be MMCT active. Along with electronic configuration, these compounds also exhibit similar ligand environment $(O, N$ donors $)$ around the metal centres to that in $\mathbf{1}$ and $\mathbf{2}$, which prompt us to study related energy transfer processes in $\mathbf{1}$ and $\mathbf{2}$ with UV-Vis spectroscopy. The UV-Vis absorption spectra shown in Fig. 5, were measured in the solid state. The visible part of the electronic spectrum of compounds $\mathbf{1}$ and $\mathbf{2}$ is very similar to spectrum of $\left[\mathrm{Cr}(\text { bpy })_{2}\left(\mathrm{C}_{2} \mathrm{O}_{4}\right)\right]\left[\mathrm{Cr}(\mathrm{bpy})\left(\mathrm{C}_{2} \mathrm{O}_{4}\right)_{2}\right] \cdot 3 \mathrm{H}_{2} \mathrm{O},{ }^{19}$ indicating the presence of six-coordinated chromium(III) complexes with two different donor atoms. Since precursor $\left[\mathrm{TaO}\left(\mathrm{C}_{2} \mathrm{O}_{4}\right)_{3}\right]^{3-}$ anions 
are not isolated in the solid state, analogues $\mathrm{Nb}$-containing compound $\left(\mathrm{NH}_{4}\right)_{3}\left[\mathrm{NbO}\left(\mathrm{C}_{2} \mathrm{O}_{4}\right)_{3}\right] \cdot \mathrm{H}_{2} \mathrm{O}$ was used as a reference. ${ }^{41}$ Due to the distorted octahedral geometry of chromium(III), the lowest ${ }^{4} \mathrm{~T}_{2 \mathrm{~g}} \leftarrow{ }^{4} \mathrm{~A}_{2 \mathrm{~g}}$ transition is split into ${ }^{4} \mathrm{E}_{\mathrm{g}} \leftarrow{ }^{4} \mathrm{~B}_{1 \mathrm{~g}}$ and ${ }^{4} \mathrm{~B}_{2 \mathrm{~g}} \leftarrow{ }^{4} \mathrm{~B}_{1 \mathrm{~g}}$, and the corresponding bands are located at 511 and $450 \mathrm{~nm}$, respectively. Similarly, the second spin-allowed transition ${ }^{4} \mathrm{~T}_{1 \mathrm{~g}} \leftarrow{ }^{4} \mathrm{~A}_{2 \mathrm{~g}}$ is also split, appearing at 399 and $420 \mathrm{~nm}$. In the UV part of the spectrum stronger absorption bands are found, corresponding to ligand to metal charge transfer transitions $(\mathrm{N} \rightarrow \mathrm{Cr}$ at $308 \mathrm{~nm}$ and $\mathrm{O} \rightarrow \mathrm{Ta}$ at $268 \mathrm{~nm}$ ). The titled compound contains no additional lines other than those already present in compounds similar to starting reagents: $\left[\mathrm{Cr}(\mathrm{bpy})_{2}\left(\mathrm{C}_{2} \mathrm{O}_{4}\right)\right]\left[\mathrm{Cr}(\mathrm{bpy})\left(\mathrm{C}_{2} \mathrm{O}_{4}\right)_{2}\right] \cdot 3 \mathrm{H}_{2} \mathrm{O}^{19}$ and $\left(\mathrm{NH}_{4}\right)_{3}\left[\mathrm{NbO}\left(\mathrm{C}_{2} \mathrm{O}_{4}\right)_{3}\right] \cdot \mathrm{H}_{2} \mathrm{O} .{ }^{41}$ Collected UV-Vis spectra do not point to the occurrence of light-induced MMCT at room temperature in compounds with $\mathrm{Cr}-\mathrm{O}-\mathrm{Ta}$ bridge.

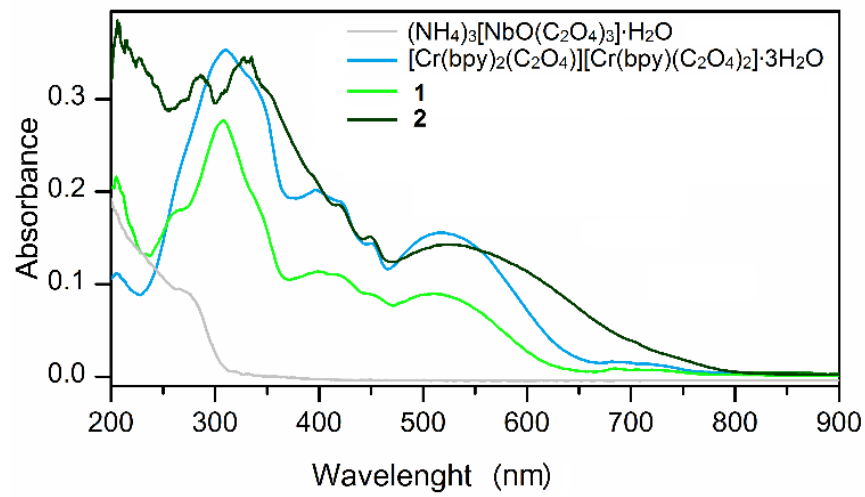

Fig. 5. Solid state UV-Vis absorption spectra of compounds: $\left[\mathrm{Cr}(\mathrm{bpy})_{2}\left(\mathrm{H}_{2} \mathrm{O}\right)(\mu\right.$ O) $\left.\mathrm{Ta}\left(\mathrm{C}_{2} \mathrm{O}_{4}\right)_{3}\right]_{2} \cdot 3.5 \mathrm{H}_{2} \mathrm{O}$ (1), [ $\mathrm{H}_{2}$ (terpy)][Cr(terpy) $\left.\left(\mathrm{C}_{2} \mathrm{O}_{4}\right)(\mu-\mathrm{O}) \mathrm{Ta}\left(\mathrm{C}_{2} \mathrm{O}_{4}\right)_{3}\right] \cdot 0.5 \mathrm{H}_{2} \mathrm{C}_{2} \mathrm{O}_{4} \cdot 2.5 \mathrm{H}_{2} \mathrm{O}$ (2), $\left[\mathrm{Cr}(\mathrm{bpy})_{2}\left(\mathrm{C}_{2} \mathrm{O}_{4}\right)\right]\left[\mathrm{Cr}(\mathrm{bpy})\left(\mathrm{C}_{2} \mathrm{O}_{4}\right)_{2}\right] \cdot 3 \mathrm{H}_{2} \mathrm{O}^{19}$ and $\left(\mathrm{NH}_{4}\right)_{3}\left[\mathrm{NbO}\left(\mathrm{C}_{2} \mathrm{O}_{4}\right)_{3}\right] \cdot \mathrm{H}_{2} \mathrm{O}^{41}$.

\section{IR spectroscopy}

The IR spectra of the two complexes are in agreement with the results of the X-ray analysis, and show the absorption bands that can be attributed to the vibrations of bidentate oxalate groups, bridging oxo atoms, and $\mathrm{N}$-donor aromatic (bpy in $\mathbf{1}$, terpy in 2) ligands. The bands of medium intensity found in the region $3670-3150 \mathrm{~cm}^{-1}$ originate from the $\mathrm{O}-\mathrm{H}$ stretching vibration $[v(\mathrm{OH})]$ of water molecules and oxalic acid molecules (in 2). The absorption bands characteristic for the bidentate oxalate ligands are given in Table 3. ${ }^{14-17}$ Asymmetric stretching vibration bands of the $\mathrm{Cr}-\mathrm{O}-\mathrm{Ta}$ core appear at $869 \mathrm{~cm}^{-1}$ in 1 and $874 \mathrm{~cm}^{-1}$ in 2, pointing to similar vibrational behaviour of the oxo-bridge in both compounds. Other absorption bands of significant intensity in the spectra correspond to different vibrations of coordinated $2,2^{\prime}$-bipyridine or terpyridine. ${ }^{42}$
Table 3 Absorption bands $\left(\mathrm{cm}^{-1}\right)$ of the bidentate oxalate groups in compounds $\mathbf{1}$ and 2. Comparison between experimental vibrational frequencies (Exp.) with theoretical ones deduced from the optimized (opt) and experimental (exp) atomic structures of 1 .

\begin{tabular}{|c|c|c|c|}
\hline Comp. & $v_{\text {asymmetric }}(\mathrm{CO})$ & $v_{\text {symmetric }}(\mathrm{CO})$ & $\delta(\mathrm{OCO})$ \\
\hline \multicolumn{4}{|c|}{ Experimental } \\
\hline $\mathbf{1}$ & $\begin{array}{c}1752,17201689, \\
1679\end{array}$ & $1384,1343,1225$ & 806 \\
\hline $\mathbf{2}$ & $1746,1716,1686$, & $1371,1357,1246$ & 803 \\
\hline \multicolumn{4}{|c|}{ DFT } \\
\hline $\mathbf{1}$, opt & $\begin{array}{c}1728,1680,1640, \\
1627\end{array}$ & $\begin{array}{c}1359,1328,1238, \\
1229,1194,1180\end{array}$ & $786,780,771$ \\
\hline $\mathbf{1}$, exp & $\begin{array}{c}2006,1983,1965, \\
1920,1849,1784\end{array}$ & $\begin{array}{c}1383,1374,1350, \\
1337,1300,1245\end{array}$ & $742,741,740$ \\
\hline
\end{tabular}

DFT simulations were performed to support assignments of the IR absorption bands in compound 1. Before analysing the DFT results, simulations based on the experimentally refined and the DFT optimized structure have been compared. For these two $\mathrm{PBE}+\mathrm{U}$ simulations of one isolated heterodinuclear $\left[\mathrm{Cr}(\mathrm{bpy})_{2}\left(\mathrm{H}_{2} \mathrm{O}\right)(\mu-\mathrm{O}) \mathrm{Ta}\left(\mathrm{C}_{2} \mathrm{O}_{4}\right)_{3}\right]$ unit in a box with cell parameters has been considered, allowing to avoid artificial interactions between the periodically duplicate units (10 ̊ at least). While these two atomic structures are very close in terms of bond lengths, their vibrational signatures are significantly different. In particular, the IR spectrum related to the optimized model is in very good agreement with the experimental IR spectrum, in contrast to the simulation related to the experimental structure. Such an observation is a consequence of the difficulty to accurately describe the atomic position of light elements with $\mathrm{X}$-ray diffraction, in particular when heavier elements are also present in the sample ( $\mathrm{Cr}$ and $\mathrm{Ta}$ here). While such a loss of contrast does not influence drastically the average bond lengths, it has a large impact on the description of the vibrational modes. For instance, the $\mathrm{O}-\mathrm{H}$ stretching vibrations $[\mathrm{v}(\mathrm{OH})]$ of water molecules evidenced in Fig. 6, which are experimentally observed in the region $3670-3150 \mathrm{~cm}^{-1}$, are simulated at frequencies going beyond $4000 \mathrm{~cm}^{-1}$ (7478 and $5129 \mathrm{~cm}^{-1}$ ), and in the region $3500-3000 \mathrm{~cm}^{-1}$, when considering the experimental and the optimized structures, respectively.

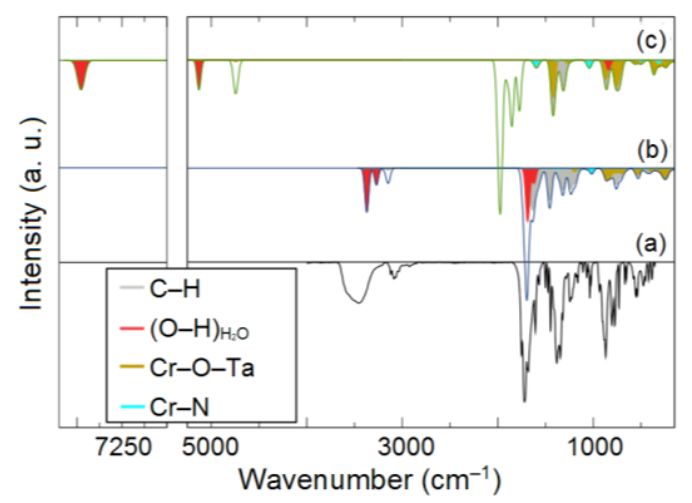

Fig. 6. Comparison of the experimental (a) and theoretical projected IR spectra of 1 based on the optimized model (b) and the experimental refined structure (c). 
Similarly, a huge number of imaginary modes (negative frequencies) are found when using the experimental structural parameters in the IR spectrum calculations (48 modes in the range 2650-9 $\mathrm{cm}^{-1}$ ), while only very few for the optimized model (18 modes in the range $24-480 \mathrm{~cm}^{-1}$ ). The fact that imaginary modes are still obtained with the optimized structure is related to our strategy which consists to extract one $\left[\mathrm{Cr}(\mathrm{bpy})_{2}\left(\mathrm{H}_{2} \mathrm{O}\right)(\mu-\mathrm{O}) \mathrm{Ta}\left(\mathrm{C}_{2} \mathrm{O}_{4}\right)_{3}\right]$ unit from the crystal (which has been optimized) to do the IR spectrum simulation. Indeed, such vibrational mode calculations are highly demanding both in terms of computational power and memory if considering the full crystal. Our strategy leads to neglect the interconnections between the units and the hydrogen-bonding network. The description of the vibrational modes of the outer part of the molecule (mainly $\mathrm{C}-\mathrm{H}$ groups) is thus influenced. It explains the 18 imaginary frequencies in the region $24-480 \mathrm{~cm}^{-1}$. It should be noticed that it has no consequence on the description of the vibrational modes related to the first coordination sphere of $\mathrm{Cr}$ and Ta atoms. In particular, as shown in Fig. 6, the vibrational modes implying the ligands coordinated to $\mathrm{Cr}$ and $\mathrm{Ta}$ are well reproduced when optimized atomic structure was considered. To summarize, the main interest to the comparison between IR experiments and simulations is to confirm that the atomic structure after geometry optimization properly describes the experimental data (IR spectrum) and thus can be used with confidence for the determination of the magnetic properties. In addition, the optimized structure provides better atomic positions for the hydrogen atoms, essential for the proper description of the properties of the compound.

\section{Magnetization study}

Magnetization of compounds $\mathbf{1}$ and $\mathbf{2}$ was measured as a function of temperature $M(T)$ in different magnetic fields, and although the behaviour is paramagnetic-like, two modes of measurement were applied: after cooling in zero field (ZFC) and after cooling in field (FC) (field-cooled) modes, to check their complete overlapping down to $2 \mathrm{~K}$. Also, the field dependences of magnetization, $M(H)$, i.e. magnetic hysteresis loops are reversible at all measured temperatures down to $2 \mathrm{~K}$, which also indicates the absence of long-range magnetic order, and points to paramagnetic-like behaviour. Due to the measured linearity of $M(H)$ at different temperatures considerably above 1000 Oe, the magnetic susceptibility $\chi$ was calculated in field of $1000 \mathrm{Oe}$ (shown in Fig. 7) as a good physical quantity for the Van Vleck type of analysis. In accordance with structure of compounds 1 and 2, the magnetic susceptibility shown in Fig. 7 was modelled supposing the spin $S=3 / 2$ of $\mathrm{Cr}^{\prime \prime \prime}$ ions having the zero-field splitting type of single ion anisotropy with neglected transversal term, using the powder approximation. Therefore, the following formulas ${ }^{43}$ were used:

$$
\begin{aligned}
& \chi(T)=\left(\chi_{z}+2 \chi_{x}\right) / 3 \\
& \chi_{z}=\frac{N g^{2} \mu_{B}^{2}}{4 k T} \frac{1+9 \exp (-2 \mathrm{D} / k T)}{1+\exp (-2 D / k T)} \\
& \chi_{x}=\frac{N g^{2} \mu_{B}^{2}}{k T} \frac{1+3 k T / 4 D(1-\exp (-2 D / k T)}{1+\exp (-2 D / k T)}
\end{aligned}
$$

where $g$ is $g$-factor, $D$ is axial zero-field splitting parameter, and other quantities have their usual meaning ( $N$ Avogadro number, $k$ Boltzmann constant, $\mu_{\mathrm{B}}$ Bohr magneton). For compound $\mathbf{1}$ the best fitting was obtained for parameters $|D|=1.37(2) \mathrm{cm}^{-1}, g=$ 1.976(1), which is in accordance with usual value for chromium(III). ${ }^{36,44,45}$ The obtained zero-field splitting term $D$ is in good accordance with EPR results (see Electron Paramagnetic Resonance Study), and being also in very good correlation with previously determined $D$ for $\mathrm{Cr}^{\prime \prime \prime}$ in similar environments. ${ }^{36,44,45}$ In compound $\mathbf{2}$ fitting gave slightly higher value of parameter $D$ [3.34(5) $\mathrm{cm}^{-1}$ ] and $g$ value of 1.990(3). ${ }^{46}$ Values of the magnetization and a very good overlap between the measured data and the fitted function confirm that spin comes only from the $\mathrm{Cr}^{\prime \prime \prime}$ ions and that there is no possibility of superexchange over the oxo-bridge due to charge transfer to the $\mathrm{Ta}^{\mathrm{V}}$ ion. Also, other paths of non-negligible interactions among neighbouring Cr'll ions are excluded, since the shortest $\mathrm{Cr} \cdots \mathrm{Cr}$ intermolecular distance is 9.066(2) $\AA$ in 1 and 7.517(2) $\AA$ in 2.

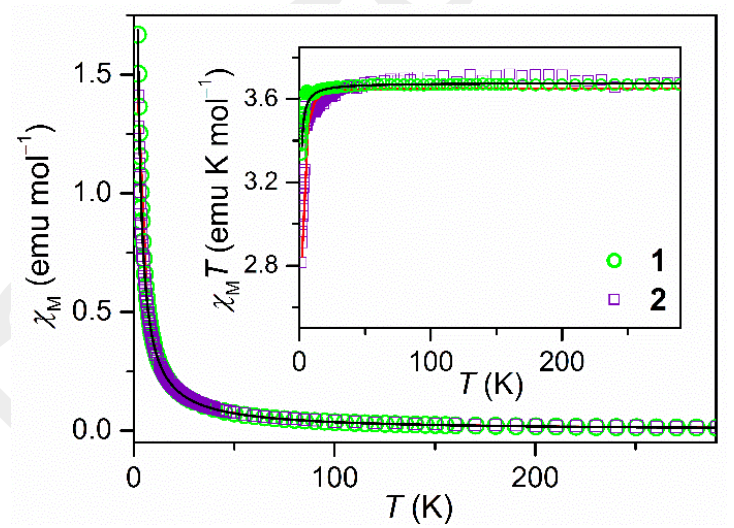

Fig. 7. Temperature dependence of molar magnetic susceptibility $\left(\chi_{\mathrm{M}}\right)$ for $\mathbf{1}$ and 2 measured in the field of 1000 Oe. Inset shows temperature dependence of the susceptibility and temperature product. The solid black and red lines represent the corresponding fitting curves for $\mathbf{1}$ and $\mathbf{2}$, respectively.

\section{Electron paramagnetic resonance study}

The EPR measurements were performed to characterize the magnetic anisotropy of the investigated compound, which stems from a local environment. Namely, this spectroscopic technique is invaluable in quantifying magnetic anisotropy, as well as in distinguishing among various possible anisotropy terms. ${ }^{45-51}$ The intensity of the room-temperature X-band EPR spectrum of $1, \chi_{\mathrm{EPR}}=6(1) \times 10^{-3} \mathrm{emu} \mathrm{mol}^{-1}$, which corresponds to the static magnetic susceptibility, 48,51 was calibrated with a reference paramagnetic sample. This value nicely corresponds to the value of $6.2 \times 10^{-3} \mathrm{emu} \mathrm{mol}^{-1}$, predicted by the Curie law for isolated Cr'II ions. The X-band EPR spectrum, shown in Fig. 8 a, is typical for a paramagnetic centre with sizable magnetic anisotropy. If the latter was absent, a single spectral component would emerge at the field value of $B_{0}=h v / g \mu_{B}=0.352 \mathrm{mT}$, with $h$ and $\mu_{B}$ being the Planck constant and the Bohr magneton, respectively, and $g=1.98$ the $g$-factor of the $\mathrm{Cr}^{\prime \prime \prime}(S=3 / 2)$ magnetic moments. Such a $g$-factor is slightly reduced from the free electron value and is typical for a $\mathrm{Cr}^{\prime \prime l}$ ion, ${ }^{51}$ it has been recently observed in a structurally related complex having a 
$\left\{\mathrm{Cr}_{2}(\mu-\mathrm{O})_{4} \mathrm{Nb}_{2}\right\}$ core. ${ }^{36}$ In the latter case, the room-temperature $X$-band EPR spectrum is indeed centred around $B_{0}$ due to sizable intradimer exchange interaction, while this is not the case in $\mathbf{1 .}$ Further insight into magnetic anisotropy of the investigated compound is provided by high-frequency measurements, which allow much better spectral resolution (Figs. $8 \mathrm{~b}$ and $8 \mathrm{c}$ ). The overall shape of the spectrum at a given frequency remains unchanged within the whole temperature range, as only small changes of the relative peak intensities and peak positions are observed (Fig. 8c). This is again due to the fact that the paramagnetic centres are isolated, in contrast to the recently published complex in which two $\mathrm{Cr}^{\prime \prime \prime}$ ions are connected by two triatomic $-\mathrm{O}-\mathrm{Nb}^{\mathrm{V}}-\mathrm{O}-$ bridges. $^{36}$ The multi-feature highfrequency spectra are due to single-ion anisotropy, given by the Hamiltonian:

$$
H=\left[\left(S^{z}\right)^{2}-2 S(S+1) / 3\right]+E\left[\left(S^{x}\right)^{2}-\left(S^{y}\right)^{2}\right]
$$
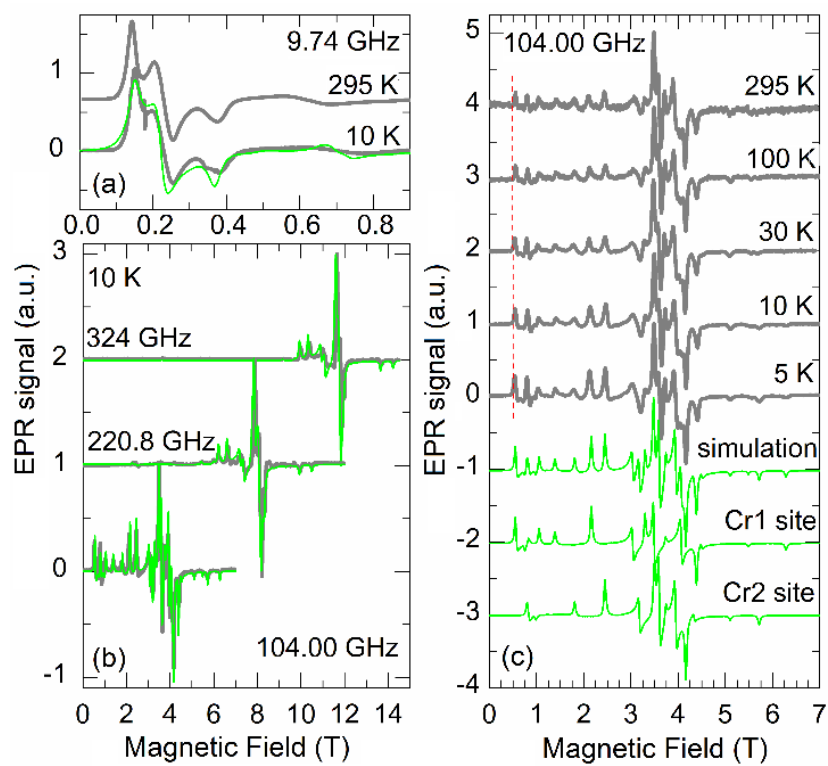

Fig. 8. The temperature and frequency dependence of normalized EPR spectra of 1 . The spectra were recorded in the X-band (a) and at various high frequencies (b), (c). Thick (grey) lines correspond to the experimental data, while thin (green) lines show simulations, as described in the text. The two spectral components of the fit (corresponding to the two crystallographically inequivalent $\mathrm{Cr}$ sites) are also shown separately in (c). The vertical dashed line in (c) indicates a small shift of a selected peak with temperature.

The high-frequency spectra at $10 \mathrm{~K}$ for two crystallographically inequivalent $\mathrm{Cr}$ sites were simulated using this Hamiltonian, giving the following anisotropy constants $D_{\mathrm{cr} 1}=1.2 \mathrm{~cm}^{-1}, E_{\mathrm{Cr} 1}=$ $0.15 \mathrm{~cm}^{-1}$ and $D_{\mathrm{cr} 2}=0.9 \mathrm{~cm}^{-1} \mathrm{~K}, E_{\mathrm{Cr} 2}=0.12 \mathrm{~cm}^{-1}$ and $g=1.98$ (Figs. $8 \mathrm{~b}$ and $8 \mathrm{c}$ ). These anisotropy values are of the same order of magnitude as the ones in the structurally related compound with $\mathrm{Cr}-\mathrm{O}-\mathrm{Nb}$ bridges $^{36}$ and are typical for a $\mathrm{Cr}^{\text {III }}$ ion in a distorted octahedral crystal field. $44,45,51$ The same parameters also explain the shape of the X-band spectrum (Fig. 8a), although this spectrum alone could be reproduced already with a single $(D, E)$ anisotropy pair due to its reduced spectral resolution.

Finally, the zero-field splitting parameters have been estimated from the DFT calculations using the optimized structural model.
Even though compound $\mathbf{1}$ has two $\mathrm{Cr}^{\prime \prime \prime}-\mathrm{Ta}^{\mathrm{V}}$ dinuclear moieties in the asymmetric unit, the atomic structures of the two $\mathrm{Cr}^{\text {III }}$ sites are very close to each other from a structural point of view. Crystallographic inequivalence comes from the fact that compound 1 crystalize in a low symmetry $\left(P 2_{1} / c\right)$, as a consequence of the organic part of the molecule and not of the first shell of $\mathrm{Cr}^{\prime \prime \prime}$ atoms. This is evident from the geometry around metal centres, which are very similar for the two inequivalent $\mathrm{Cr}^{\mathrm{III}}-\mathrm{Ta}^{\mathrm{V}}$ dinuclear moieties. Such small structural differences in the coordination sphere of $\mathrm{Cr}^{\prime \prime \prime}$ ions are below the accuracy of DFT calculations, which prevents us to distinguish two sets of zero-field splitting parameters for the two inequivalent $\mathrm{Cr}^{\text {III }}$ ions. A similar strategy as for previously reported oxo-bridged $\mathrm{Cr}-\mathrm{Nb}$ compound was used, ${ }^{36}$ based on the estimates of the $D$ and $E$ parameters from the knowledge of the single-ion anisotropy, represented in Fig. 9a. Such estimation relies on a specific convention, which defines the principal axes of the zero-filed splitting tensor. Here, the $z$-axis is defined as the most different one and $x$ as the harder magnetization axis with respect to $y$ direction. Such a convention leads to $D>0, D>3 E$. In that way, an axial $(D=0.54$ $\left.\mathrm{cm}^{-1}\right)$ and rhombic $\left(E=0.05 \mathrm{~cm}^{-1}\right)$ zero-filed splitting parameters have been determined, showing good agreement with the experimental values obtained from EPR spectroscopy. The fact that the easy and hard magnetization axes are pointing along the $\mathrm{Cr}-\mathrm{OH}_{2}$ and $\mathrm{Cr}-\mathrm{O}-\mathrm{Ta}$ bonds, respectively, can be explained considering the orbital moment of $\mathrm{Cr}^{\text {III }}$ ion. Indeed, as demonstrated in the Bruno's theory, ${ }^{52}$ when the magnetic anisotropy is dictated by the spin-orbit coupling, the easy magnetic moments axis is defined by the direction for which the orbital moment is maximum. To emphasize the present argument, the orbital moment anisotropy (OMA) has been drawn on Fig. 9b, which is defined as:

$O M A_{[u v w]}=m_{i,[u v w]}-m_{l,\left[u_{0} v_{0} w_{0}\right]}$

where $[u v w]$ is a general direction and $\left[u_{0} v_{0} w_{0}\right]$ the direction giving the smallest orbital moment value. It clearly points that the easy magnetization axis (red colour in Fig. 9a) is directly related to the direction of the largest orbital moment value (blue colour in Fig. 9b). Such large orbital moment direction is a consequence of the occupancy of the " $t_{2 g}$-like" orbitals in the distorted octahedral environment by three unpaired electrons.

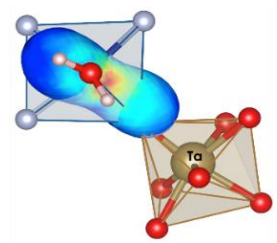

(a)

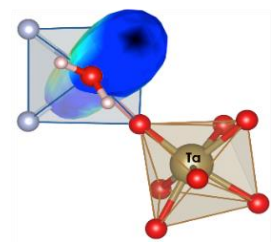

(b)
Fig. 9. (a) Single-ion anisotropy and (b) orbital moment anisotropy of the complex extracted from the optimized structure.

Finally, regarding the high-frequency EPR spectra, we note that with increasing temperature from 10 to $295 \mathrm{~K}$ the lowest-field 
spectral peak slightly shifts to higher fields, which can be understood as a reduction of the single-ion anisotropy parameters due to lattice expansion.

\section{Conclusion}

Air and moisture stable tantalum complexes are quite limited. The aqueous (oxalato)tantalate(V) solution has again proved to be an excellent choice of tantalum containing mononuclear anions for preparation of different heterometallic compounds. Moreover, herein we report the oxo-bridged $\mathrm{Cr}-\mathrm{O}-\mathrm{Ta}$ core which is for the first time isolated in the molecular compound. The terminal $\mathrm{Ta}=\mathrm{O}$ from the $\mathrm{Ta}\left[\mathrm{O}\left(\mathrm{C}_{2} \mathrm{O}_{4}\right)_{3}\right]^{3-}$ anion reacts with $\mathrm{Cr}$ 'III from $\left[\mathrm{Cr}(\mathrm{bpy})_{2}\left(\mathrm{H}_{2} \mathrm{O}\right)_{2}\right]^{3+}$ and $\left[\mathrm{Cr}(\text { terpy })\left(\mathrm{C}_{2} \mathrm{O}_{4}\right)\left(\mathrm{H}_{2} \mathrm{O}\right)\right]^{+}$cations, forming a dinucelar complexes $\mathrm{Cr}(\mathrm{bpy})_{2}\left(\mathrm{H}_{2} \mathrm{O}\right)(\mu$ O) $\left.\mathrm{Ta}\left(\mathrm{C}_{2} \mathrm{O}_{4}\right)_{3}\right]_{2} \cdot 3.5 \mathrm{H}_{2} \mathrm{O} \quad(\mathbf{1})$ and $\left[\mathrm{H}_{2}\right.$ (terpy) $]\left[\mathrm{Cr}(\right.$ terpy $)\left(\mathrm{C}_{2} \mathrm{O}_{4}\right)(\mu$ O) $\left.\mathrm{Ta}\left(\mathrm{C}_{2} \mathrm{O}_{4}\right)_{3}\right] \cdot 0.5 \mathrm{H}_{2} \mathrm{C}_{2} \mathrm{O}_{4} \cdot 2.5 \mathrm{H}_{2} \mathrm{O}(2)$.

Oxo-bridged metals are well known functional intramolecular motifs, exhibiting interesting properties in complexes, and discovery of new combinations of metals with different electronic configurations and redox potentials represents a valuable contribution to the design of new materials. Occurrence of MMCT in compounds $\mathbf{1}$ and $\mathbf{2}$ was tested with solid state UV-Vis spectroscopy; however no additional features compared to spectra of starting reagents were observed. Magnetic susceptibility measurements on SQUID have shown typical paramagnetic behaviour for both compounds, with no unusual magnetic features, pointing that charge transfer from $\mathrm{Cr}^{\prime \prime \prime}$ to $\mathrm{Ta}^{\vee}$ through oxo-bridge is not taking place as the temperature is lowered. In order to characterize the new $\mathrm{Cr}-\mathrm{O}-$ Ta core in more detail, structural, vibrational and magnetic properties of compound $\mathbf{1}$ have further been investigated with DFT calculations, showing a very good match with the experimental data.

\section{Conflicts of interest}

There are no conflicts to declare.

\section{Acknowledgements}

This work has been supported by the Croatian Science Foundation under the project IP-2014-09-4079. D.P. would like to acknowledge the partial support of Croatian Science Foundation through the project UIP-2014-09-8276. A.Z. acknowledges the financial support of the Slovenian Research Agency through the Program No. P1-0125 and Project Bi-US/1415-039. NHMFL is supported by the NSF through the cooperative agreement DMR-1157490, the State of Florida and the Department of Energy. X.R. and W.L.D.H. thank CCIPL (Nantes) computing centre for computational facilities. The authors would like to thank Dr Emmanuel Wenger and CRM2 laboratory (University of Lorraine) for the X-ray data collection of compound 2 .

\section{Notes and references}

1 J. B. Vincent, G. L. Olivier-Lilley and B. A. Averill, Chem. Rev., 1990, 90, 1447-1467.

2 A. Yamaguchi, T. Takashima, K. Hashimoto and R. Nakamura, Chem. Mater., 2017, 29, 7234-7242.

3 H. Han and H. Frei, J. Phys. Chem. C, 2008, 112, 8391-8399.

4 H. Han and H. Frei, J. Phys. Chem. C, 2008, 112, 16156-16159.

5 R. Lomoth and S. Ott, Dalton Trans., 2009, 0, 9952-9959.

6 Z. Barandiarán, A. Meijerinkc and L. Seijo, Phys.Chem.Chem.Phys., 2015, 17, 19874-19884.

7 D.-L. Long, R. Tsunashima and L. Cronin, Angew. Chemie Int. Ed., 2010, 49, 1736-1758.

8 T. Huang, X. Wu, X. Song, H. Xu, T. I. Smirnova, W. W. Weare and R. D. Sommer, Dalton Trans., 2015, 44, 18937-18944.

9 T. Huang, X. Wu, W. W. Weare and R. D. Sommer, Eur. J. Inorg. Chem., 2014, 5662-5674

10 J. Falzone, J. Nguyen, W. W. Weare, R. D. Sommer and P. D. Boyle, Chem. Comm., 2014, 50, 2139-2141.

$11 \mathrm{X}$. Wu, T. Huang, T. T. Lekich, R. D. Sommer and W. W. Weare, Inorg. Chem., 2015, 54, 5322-5328.

12 E. S. Koumousi, I.-R. Jeon, Q. Gao, P. Dechambenoit, D. N. Woodruff, P. Merzeau, L. Buisson, X. Jia, D. Li, F. Volatron, C. Mathonière and R. Clérac, J. Am. Chem. Soc., 2014, 136, 15461-15464.

13 T. J. Morsing, J. Bendix, H. Weihe and A. Døssing, Inorg. Chem., 2014, 53, 2996-3003.

14 L. Androš, M. Jurić, J. Popović and P. Planinić, RSC Adv., 2014 4, 37051-37060.

15 L. Androš, M. Jurić, J. Popović, A. Šantić, P. Lazić, M. Benčina, M. Valant, N. Brničević and Pavica Planinić, Inorg. Chem., 2013, 52, 14299-14308.

16 L. Androš Dubraja, D. Matković-Čalogović and P. Planinić, CrystEngComm, 2015, 17, 2021-2029.

17 L. Androš, D. Matković-Čalogović, and P. Planinić, CrystEngComm, 2013, 15, 533-543.

18 L. Androš, M. Jurić, P. Planinić, D. Žilić, B. Rakvin and K. Molčanov, Polyhedron, 2010, 29, 1291-1298.

19 L. Androš, M. Jurić, K. Molčanov and P. Planinić, Dalton Trans., 2012, 41, 14611-14624.

20 Agilent, CrysAlis PRO. Agilent Technologies Ltd, Yarnton, Oxfordshire, England, 2014.

21 Bruker, SAINT V8.34A, Bruker AXS Inc., Madison, WI, 2013.

22 A. Altomare, G. Cascarano, C. Giacovazzo and A. Guagliardi, J. Appl. Crystallogr., 1994, 7, 435.

23 G. M. Sheldrick, Acta Cryst., 2015, C71, 3-8.

24 L. J. Farrugia, J. Appl. Crystallogr., 2012, 45, 849-854.

25 A. L. Spek, Acta Crystallogr. 2009, D65, 148-155.

26 K. Momma and F. Izumi, J. Appl. Crystallogr., 2011, 44, 12721276.

27 C. F. Macrae, P. R. Edgington, P. McCabe, E. Pidcock, G. P. Shields, R. Taylor, M. Towler and J. van de Streek, J. Appl. Crystallogr., 2006, 39, 453-457.

28 A. K. Hassan, L. A. Pardi, J. Krzystek, A. Sienkiewicz, P. Goy, M. Rohrer and L.-C. Brunel, J. Magn. Reson., 2000, 142, 300-312.

29 S. Stoll and A. Schweiger, J. Magn. Reson., 2006, 178, 42-55.

30 J. P. Perdew, K. Burke and M. Ernzerhof, Phys. Rev. Lett., 1996, 77, 3865-3868.

31 G. Kresse and D. Joubert, Phys. Rev. B, 1999, 59, 1758-1775.

32 G. Kresse and J. Furthmüller, Phys. Rev. B, 1996, 54, 1116911186.

33 G. Kresse and J. Furthmüller, Comput. Mater. Sci., 1996, 6, 1550.

34 A. V. Krukau, O. A. Vydrov, A. F. Izmaylov and G. E. Scuseria, J. Chem. Phys., 2006, 125, 224106.

35 S. L. Dudarev, G. A. Botton, S. Y. Savrasov, C. J. Humphreys and A. P. Sutton, Phys. Rev. B, 1998, 57, 1505-1509. 
36 M. Jurić, L. Androš Dubraja, D. Pajić, F. Torić, A. Zorko, A. Ozarowski, V. Despoja, W. Lafargue-Dit-Hauret and X. Rocquefelte, Inorg. Chem., 2017, 56, 6879-6889.

37 L. Androš, M. Jurić, P. Planinić, D. Žilić, B. Rakvin and K. Molčanov, Polyhedron, 2010, 29, 1291-1298.

38 M. Jurić, L. Androš Dubraja, J. Popović, K. Molčanov, F. Torić, D. Pajić and I. Lončarić, Dalton Trans., 2018, 47, 4183-4190.

39 N. E. Brese and M. O'Keeffe, Acta Crystallogr., Sect. B, 1991, 47, 192-197.

40 C. R. Groom and F. H. Allen, Angew. Chem. Int. Ed., 2014, 53 662-671.

41 M. Jurić, J. Popović, A. Šantić, K. Molčanov, N. Brničević and P. Planinić, Inorg. Chem., 2013, 52, 1832-1842.

42 K. Nakamoto, Infrared and Raman Spectra of Inorganic and Coordination Compounds, 6th ed., John Wiley: New York, 2009.

43 O. Kahn, Molecular Magnetism, VCH-Verlag, Weinheim, New York, 1993.

44 D. Žilić, L. Androš, Y. Krupskaya, V. Kataev and B. Büchner, Appl Magn Reson., 2015, 46, 309-321.

45 L. Androš, M. Jurić, J. Popović, D. Pajić, K. Zadro, K. Molčanov, D. Žilić and P. Planinić, Eur. J. Inorg. Chem., 2014, 5703-5713.

46 L. Androš Dubraja, M. Jurić, J. Popović, D. Pajić, Y. Krupskaya, V. Kataev, B. Búchner and D. Žilić, Dalton Trans., 2018, 47, 3992-4000.

47 A. Zorko, S. Nellutla, J. van Tol, L. C. Brunel, F. Bert, F. Duc, J.C. Trombe, M. A. de Vries, A. Harrison and P. Mendels, Phys. Rev. Lett., 2008, 101, 026405.

48 M. Herak, A. Zorko, D. Arčon, A. Potočnik, M. Klanjšek, J. van Tol, A. Ozarowski and H. Berger, Phys. Rev. B, 2011, 84, 184436.

49 A. Zorko, M. Pregelj, A. Potočnik, J. van Tol, A. Ozarowski, V. Simonet, P. Lejay, S. Petit and R. Ballou. Phys. Rev. Lett., 2011, 107, 257203

50 A. Zorko, F. Bert, A. Ozarowski, J. van Tol, D. Boldrin, A. S. Wills and P. Mendels, Phys. Rev. B, 2013, 88, 144419.

51 A. Abragam and B. Bleaney, Electron Paramagnetic Resonance of Transition lons, Oxford University Press: Oxford, 1970.

52 P. Bruno, Phys. Rev. B, 1989, 39, 865. 